\title{
AS MULHERES ANDAM MAL \\ Das aulas erráticas às aulas vadias na emergência dos mapas do medo
}

\author{
LAS MUJERES ANDAN MAL \\ De las clases erráticas a las clases perras en la emergencia de los mapas \\ del miedo
}

\author{
WOMEN ARE BAD WALKER \\ From erratic classes to bitch classes in emergence of fear maps
}

\author{
Denise Pereira Rachel ${ }^{1}$
}

\begin{abstract}
RESUMO
Este artigo discute as experiências com as aulas erráticas, durante o ano de 2015, como proposições de um diálogo entre a educação básica e a universidade pública, pelo Coletivo Parabelo. Ao acionarmos aulas erráticas em uma abordagem cartográfica das errâncias urbanas, tivemos de nos confrontar com questões interseccionais, relativas a gênero, raça e classe. Tais questões convocaram uma breve genealogia das errâncias urbanas, para promover uma crítica acerca da concepção de que as mulheres andam mal.
\end{abstract}

PALAVRAS-CHAVE: aula errática, errância urbana, interseccionalidade, Coletivo Parabelo, pedagogia da performance.

\section{RESUMEN}

Este artículo discute las experiencias con las clases erráticas, durante el año 2015, como proposiciones de un diálogo entre la educación básica y la universidad pública, por el Coletivo Parabelo. Al accionar las clases erráticas en un abordaje cartográfico de las errâncias urbanas, tuvimos que enfrentarnos a cuestiones interseccionales, relativas a género, raza y clase. Tales cuestiones convocaron una breve genealogía de las errâncias urbanas, para promover una crítica acerca de la concepción de que las mujeres andan mal.

PALABRAS CLAVE: clases erráticas, errância urbana, interseccionalidad, Coletivo Parabelo, pedagogía de la performance.

\section{ABSTRACT}

This article discusses the experiences with the erratic classes, during the year 2015, as propositions of a dialogue between basic education and the public university, by Coletivo Parabelo. By engaging in erratic classes in a cartographic approach to urban errancy, we had to confront intersectional questions about gender, race, and class.

\footnotetext{
${ }^{1}$ Professora performer pesquisadora do CIEJA Ermelino Matarazzo e integrante do Coletivo Parabelo. Doutoranda em Arte e Educação no PPG/IA-UNESP, com pesquisa em andamento em torno de pedagogias da performance, sob orientação de Carminda Mendes Andre. E-mail: deniserachel80@gmail.com.
} 
Such questions have convoked a brief genealogy of urban errancy to promote a critique of the notion that women are bad walker.

KEYWORDS: erratic classes; urban errancy; intersectionality; Coletivo Parabelo, performance pedagogy.

Alguns dos sintomas mais evidentes da desintegração social só são reconhecidos como um problema sério após assumirem tamanha proporção epidêmica que parecem não ter solução.

(Angela Davis)

Em nosso mundo de hoje, quando, mais do que nunca, os objetos intermedeiam nossas ações, as grandes cidades frequentemente nos aparecem como monstruosas, intratáveis, ameaçadoras da integridade social e individual, pelo fato de que elas separam em lugar de unir e nos deixam a impressão de que empobrecem a vida cotidiana ao invés de melhorá-la.

(Milton Santos)

Agosto de 2015, retomávamos as aulas após um breve período de recesso, era uma turma de Módulo IV do período da manhã, em um projeto voltado para a educação de jovens e adultos, CIEJA Ermelino Matarazzo ${ }^{2}$. Uma turma composta majoritariamente por mulheres negras que carregavam suas histórias de proibições e de exclusão, as quais foram desafiadas para que pudessem estar ali, naquelas carteiras, aguardando o início da aula enquanto conversavam entre si. Neste semestre que iniciava, daria prosseguimento a um trabalho realizado anteriormente com o que tem sido chamado de pedagogia da performance, conforme a perspectiva desenvolvida na pesquisa de mestrado intitulada Adote o artista não deixe ele virar professor: reflexões em torno do híbrido professor-performer. No decorrer desta pesquisa, problematizei as separações pré-estabelecidas entre os papeis de professora, performadora e pesquisadora sedimentados ao longo da minha trajetória de vida até então. Para tanto, elaborei dois entendimentos de aula, nos quais coloquei em questão tais distinções: a aula de performance e a aula performática.

2 O CIEJA Ermelino Matarazzo é um projeto especial de educação oferecido pela prefeitura de São Paulo, voltado para o ensino de jovens e adultos que por algum motivo não puderam frequentar ou concluir o ensino fundamental na idade considerada certa. Esta unidade do CIEJA se localiza na zona leste de São Paulo, como o próprio nome sugere, no bairro de Ermelino Matarazzo. Há mais 13 unidades em funcionamento, espalhadas por diferentes regiões da cidade. Atuo como professora performer nesta instituição desde 2012, desenvolvendo aulas performáticas junto ao Coletivo Parabelo. Para mais informações vide: www.coletivoparabelo. com 
As aulas de performance, em resumo, consistem em um trabalho de contextualização da arte da performance no âmbito da produção artística contemporânea, ao utilizar como referência a abordagem triangular de Ana Mae Barbosa $^{3}$. Desse modo, a apreciação de um vídeo que registra a performance da artista japonesa Yoko Ono, em Cut Piece (Peça Corte) ${ }^{4}$ faz emergir uma série de inquietações: "Professora, ela deve ter roupa de sobra pra fazer isso, né?", "Como ela consegue ficar parada com esse monte de gente passando a tesoura nela?", "Como as pessoas tiveram coragem de fazer isso com ela?", "Ela está constrangida! Isso é violência! Agora violência virou arte?". Então, estas inquietações são discutidas em uma relação entre o contexto da artista e o da classe, a multiplicidade de leituras possíveis daquele trabalho, o modo como a artista constrói sua poética aliado à experimentação de partituras $^{5}$ pelas estudantes, reflexões em torno de quais seriam os limites da arte em termos éticos, estéticos, políticos e de como a arte contemporânea não está comprometida com os ideais de beleza provenientes da tradição greco-romana. No caso de Yoko Ono, a princípio identificada como a mulher de John Lennon por algumas alunas, a relação com uma perspectiva feminista de entendimento da condição da mulher e o fato dela ser reconhecida à sombra do marido se voltou para uma questão anterior, de como havia poucas mulheres reconhecidas no campo das artes visuais. Pois, para grande parte da turma, artistas eram pessoas como Pablo Picasso, Vincent Van Gogh e Leonardo da Vinci. Tal concepção era um indício de que o universo das

\footnotetext{
${ }^{3}$ Para mais detalhes a respeito da relação entre a abordagem triangular e a aula de performance vide: RACHEL, Denise Pereira. Adote o Artista não deixe ele virar professor: reflexões em torno do híbrido professor performer. São Paulo: Editora Unesp, Selo Cultura Acadêmica, 2015. Disponível em: http://www.culturaacademica.com.br/catalogo-detalhe.asp?ctl_id=467.

${ }^{4}$ Referência ao registro da performance Cut Piece (1965) conforme sugerido em partitura"Performer senta-se no palco com um par de tesouras a sua frente. É anunciado ao público presente que eles podem subir no palco - um de cada vez - para cortar uma pequena parte da roupa da performer e leva-lo consigo. A performer permanece imóvel durante toda a peça. A peça termina quando a performer decidir" (tradução da autora). Vide: MUNROE, Alexandra; HENDRICKS, Jon. Yes: Yoko Ono. New York: Abrams, 2000, p. 277. Algumas das partituras de Yoko Ono estão publicadas em um catálogo da retrospectiva de sua obra, realizada no Centro Cultural Banco do Brasil, em 2008. Além do livro publicado originalmente por Yoko Ono em 1964, intitulado Grapefruit, com tradução de sua última edição, $\quad$ em $2000 . \quad$ Disponível em: http://monoskop.org/images/9/95/Ono_Yoko_Grapefruit_O_Livro_de_Instrucoes_e_Desenhos_de_Yoko _Ono.pdf. $\mathrm{O}$ registro da performance está disponível em: https://www.youtube.com/watch?v=pTGSsWVK2Eo Acesso em: jun. 2018.

${ }^{5}$ Constructo para acionar performances proposto pela comunidade artística Fluxus.
} 
artes fora apresentado para aquele grupo em uma perspectiva hegemônica, a qual remetia ao predomínio da linguagem da pintura feita supostamente por homens brancos, europeus, que já morreram, autores de obras que se tornaram artigo de museu com valor incalculável.

Em diálogo com as aulas de performance, a proposta das aulas performáticas consiste em compreender a aula de arte enquanto o próprio acontecimento performático. Desse modo, as aulas performáticas acionam a co-presença corporal na experimentação do compartilhamento de espaços tempos. Este processo se relaciona com o entendimento de feedback loop, desenvolvido pela teórica da performance Érika Fischer-Lichte. Para a autora, o feedback loop se configura como uma circulação autopoiética pela qual os corpos co-presentes retroalimentam uns aos outros e geram a si mesmos. O feedback loop ocorre de pelo menos três maneiras distintas que não estão necessariamente separadas umas das outras: no e pelo toque, quando se enfatiza qualquer tipo de contato corporal entre corpos, objetos, espaços tempos etc; na e pela troca de papeis, quando ocorre a alteração das funções dos corpos co-presentes em um determinado contexto; na e pela criação de coletividades temporárias, quando a copresença corporal proporciona a organização de ações coletivas, cooperativas e colaborativas.

Nessa perspectiva, as aulas performáticas implicam em um jogo realizado por meio de instruções, partituras, programas, proposições performativas firmadas entre os corpos co-presentes no compartilhamento dos espaços tempos, em processos imprevisíveis e indetermináveis. Dessa forma, a aula performática é responsável pelo estabelecimento de mal-entendidos (misunderstanding) conforme propõe a teórica estadunidense Peggy Phelan. Portanto, nas aulas performáticas os corpos co-presentes ativam a percepção corporal como princípio da cognição a fim de compreender o que acontece quando uma aula performática acontece, pois, perceber e entender acontecem no e pelo mesmo ato - aquilo que é percebido é entendido, aquilo que é entendido é percebido. Por fim, uma aula performática privilegia os significados emergentes ao invés de sentidos dados, impostos e subentendidos. Dessa maneira, as aulas performáticas colocam em questão as representações cognitivas nos e pelos corpos co- 
presentes que instauram espaços tempos de performação (RACHEL, 2014; MARQUES, 2017).

A aula performática se transforma em um acontecimento aberto, relacional e comunicacional, quando as representações cognitivas são questionadas, por exemplo: o que faz do professor um professor? O que faz de um aluno um aluno? O que faz de uma aula uma aula? Ou então, o que faz de um artista um artista? O que faz de um espectador um espectador? O que faz de um acontecimento artístico um acontecimento artístico? Como no dia em que entrei em sala de aula carregando uma grande pilha de folhas de sulfite brancas, depositei-a na mesa feita para uso do professor, separei uma porção e comecei a distribuir entre as carteiras das estudantes. A distribuição se estendia ao longo do tempo e aquela pilha parecia não ter fim, em meio a um burburinho crescente - "será que é prova?”, “não, acho que é aula de desenho...”, “pra que tanta folha, professora?", "acho que hoje ela acordou de ovo virado..." - Maria ${ }^{6}$ se levantou e disse "precisa de ajuda, professora?". O silêncio se instalou na expectativa do que poderia acontecer, afinal Maria havia se dirigido diretamente a mim, a propositora daquela ação. Então, separei uma porção de folhas e entreguei em suas mãos. O burburinho voltou enquanto eu e ela distribuíamos as folhas e não demorou muito para que outras se levantassem e começassem a cruzar as carteiras com pilhas de sulfite em uma distribuição interminável de folhas em branco. O que faríamos com aquelas folhas? Qual o sentido daquelas folhas? Por que a distribuíamos? Era preciso inventar. Ali estava em jogo uma ação que deslocava os sentidos convencionais de uma aula e convocava outras percepções do que poderia ser uma aula, instigava a construção de significados, se tornava um acontecimento ${ }^{7}$.

$$
* * *
$$

Retomar esta abordagem dos conceitos de aula de performance e aula performática foi uma proposta que partiu dos movimentos iniciais da pesquisa de doutorado em andamento, a qual pretende se aprofundar na problemática pertinente à ideia de aula performática. Naquele momento, atuava como professora de Linguagens

\footnotetext{
${ }^{6}$ Os nomes citados no artigo são fictícios a fim de preservar a identidade das estudantes que participaram do trabalho.

7 Escrito a partir da aula performática intitulada Tábula Rasa (2015-2017) no CIEJA Ermelino Matarazzo.
} 
e Códigos em uma proposta pedagógica referente ao projeto do CIEJA, que procura reunir diferentes áreas do conhecimento por meio da prática da docência compartilhada, em uma tentativa de construção do currículo de maneira mais coerente e coesa. No entanto, havia um grande desafio a ser enfrentado, a polivalência: durante o ano letivo deveria dar conta de conteúdos referentes às matérias de português, inglês e artes, sempre em diálogo com professores de outras áreas. Neste contexto, era preciso pensar em um projeto aglutinador de diversas áreas de conhecimento, ao mesmo tempo em que práticas de escrita, leitura e interpretação também deveriam estar envolvidas. Além disso, havia o desejo de aprofundar a indistinção entre a professora, a performadora e a pesquisadora, ao levar em conta a virada pedagógica que a dissertação de mestrado promoveu no trabalho do Coletivo Parabelo ${ }^{8}$. Para tanto, concebi o que a princípio denominei como aulas erráticas, a fim de investigar de que modo a relação entre as aulas performáticas e a prática das errâncias urbanas dialogavam com uma possível revolta da carne do assento.

Desse modo, as aulas erráticas se constituíam na prática da errância urbana, isto é, na e pela arte de andar em um constante processo de orientação, desorientação e reorientação do corpo em deslocamento pela cidade e vice-versa, ao exercitarmos uma alteridade radical com os chamados outros urbanos (JACQUES, 2012). Nesse sentido, as errâncias urbanas propiciam a ativação da co-presença corporal na experimentação de estados corporais errantes que reconfiguram a experiência corporal cotidiana urbana sensível, ao acionar a politicidade do corpo enquanto expande a noção de artisticidade (MARQUES, 2017). Cabe frisar que o Coletivo Parabelo tem identificado uma variedade de práticas de errância urbana ao investigar diversas genealogias da arte da performance, em períodos que se estendem desde o final do século XIX até o começo do século XXI: flanâncias, visitas, deambulações, experiências, derivas, fluxus, delírios ambulatórios, catalizações, persecuções, áudio passeios, zonzos, manobras, dentre outras. Por esta perspectiva, a errância urbana se constitui em uma infinidade de práticas vagabundas, em que o músculo propulsor da ação de andar não se conforma em permanecer acoplado a cadeiras e necessita vagar. A partir

\footnotetext{
${ }^{8}$ Para mais detalhes vide: MARQUES, Diego Alves. Virada pedagógica: o Coletivo Parabelo e a revolta da carne do assento. In Revista Rascunhos Uberlândia v.4 n.1, p.118-132, jan.|jun.2017.
} 
desse contexto, as aulas erráticas pretendiam questionar o que talvez seja uma das principais lições ensinadas pela escola tradicional: a aprendizagem do hábito de permanecer sentado desde a mais tenra idade. Tal fato é compreendido pela ideia de Sitzfleisch proposta pelo filósofo alemão Friedrich Nietzsche, a qual geralmente é traduzida como vida sedentária, mas que poderia ser literalmente expressa como carne de assento ou a mais conhecida bunda (MARQUES, 2017). Neste âmbito, há pelo menos trezentos anos está em curso uma crescente valorização da cultura racional, letrada, escolarizada, cada vez mais restrita a práticas de leitura e escrita com ênfase na relação olho mão, ao promover uma sobrecarga dos glúteos e a sedentarização dos hábitos corporais. Assim, a popularização do uso da cadeira como objeto cotidiano empregado nos mais diversos ambientes, parece evidenciar o surgimento do homo sedens (BAITELLO JR., 2012). Portanto, as aulas erráticas almejavam justamente instigar uma revolta contra a sobrecarga da bunda promovida pela sedentarização do ensino, ao promover um elogio à vagabundagem como criação artística.

Dessa forma, foi possível conceber uma proposta de aula errática que consistia na prática da errância urbana em uma perspectiva cartográfica, uma vez que a própria errância urbana possibilita a invenção de cartografias a partir das chamadas experiências erráticas (JACQUES, 2012). Nesse viés, o Coletivo Parabelo desenvolveu a chamada perfografia, uma contração dos termos performance e cartografia, entre os anos de 2011 e 2013. Ao longo desse período, realizamos perfografias em 12 bairros considerados periféricos da cidade de São Paulo, assim como, na cidade de Porto Alegre, no Rio Grande do Sul. As perfografias eram constituídas por errâncias urbanas que compunham cartografias de territorialização, desterritorialização e reterritorialização. Estas cartografias eram uma forma de investigar as linhas de vida que constituíam uma determinada paisagem, conforme o conceito provisório de cartografia proposto pela psicanalista, crítica e curadora de artes visuais brasileira, Suely Rolnik (1989). Segundo a autora seria contraditório conceituar de forma definitiva a cartografia, pois esta se constitui justamente pelo movimento das transformações espaço temporais que compõem o real social, ou seja, Rolnik propõe que não somente as paisagens geográficas são cartografáveis, mas também as paisagens afetivas podem ser cartografadas como forma de perceber as dinâmicas do 
desejo que compõem determinada realidade. Neste aspecto, a arte da performance se aproxima da ideia de cartografia, pois ontologicamente resiste a qualquer conceituação restritiva, está em constante movimento, se configura a partir da ação de cada performer em contextos históricos, sociais e culturais específicos.

Nesse âmbito, a concepção de aulas erráticas por meio da proposição de errâncias urbanas em uma abordagem cartográfica trazia à tona a concepção de mapa, o qual, em uma perspectiva dos campos da geografia e da linguagem, consiste em uma representação gráfica, um texto produzido a partir de determinado contexto e que pode ser lido e interpretado pelos conhecedores de seus códigos. Apesar de Suely Rolnik considerar o mapa como um "todo estático" (ROLNIK, 1989), o Coletivo Parabelo escolheu outro entendimento de mapa que se aproxima do conceito provisório de cartografia. Trabalhamos a partir da concepção de mapa como performance, conforme proposto por Richard Schechner (2006). Segundo o professor estadunidense, o mapa se constitui em uma ação de planificação do espaço tridimensional em que diferentes interesses e discursos são representados e podem ser performados tanto por quem o faz quanto por quem o lê e interpreta. Se considerarmos um mapa mundi tradicionalmente reconhecido (como a projeção de Mercator) pela perspectiva proposta por Schechner, é possível afirmar que o mapa performa as relações de poder estabelecidas pelas divisões territoriais e pela perspectiva de representação dos continentes, naqueles que estão na parte superior da carta e os que dentro dessa tradição são vistos na região inferior (divisão norte e sul). Contudo tal perspectiva é questionável em relação ao globo terrestre, o qual não apresenta concretamente nenhuma dessas divisões, senão a separação de porções de terra pelos oceanos em um movimento constante.

Através dessa perspectiva, iniciamos a primeira aula errática com a proposta de que cada um apresentasse uma cartografia ou um croqui, nomenclatura utilizada no campo da geografia em relação a representações cartográficas que não seguem as regras específicas de escalas de proporção e signos gráficos acompanhados por legenda. Este croqui deveria representar o itinerário realizado cotidianamente entre o local em que morávamos ou trabalhávamos e a escola, por meio de desenho e/ou colagem. Após a confecção destas cartografias, estas foram espalhadas na parte central da sala, de 
modo que poderíamos circular e observar as soluções encontradas para representar as percepções relativas ao itinerário residência/trabalho/escola. Então, aquelas e aqueles que sentissem vontade poderiam comentar suas impressões. Alguns comentaram sobre a riqueza de detalhes dos desenhos ou sobre o desenho irregular das ruas ou ainda sobre a distância entre a casa e a escola. Mas, algo chamou a atenção no comentário de Verônica, que afirmou morar muito próximo da escola e que, por isso, poderia vir a pé, mas preferia vir de ônibus porque tinha medo de ser assaltada. Após esse comentário outras estudantes disseram que vinham a pé, porém sempre em grupo, porque não achavam seguro andarem sozinhas por aquelas ruas representadas em cores vibrantes. Estes foram os primeiros sinais de que talvez tivéssemos ali o indício de um afeto perfografado pelas relações estabelecidas com esses itinerários: o medo.

$* * *$

Em uma destas aulas erráticas fizemos errâncias urbanas a partir da ideia de algoritmo $^{9}$ em uma perspectiva cartográfica, ao nos inspirarmos na proposta de psicogeografias algorítmicas ${ }^{10}$ do coletivo holandês Social Fiction (2001). Neste dia saímos em duplas ou trios, no meu caso, eu e mais duas alunas adolescentes, Walesca e Samanta, após a escolha de um algoritmo que deveria se repetir sistematicamente. Primeira à esquerda, segunda à direita, segunda à esquerda. Repetíamos enquanto caminhávamos pelas ruas de Ermelino, como se fosse uma garantia de segurança, algo que não poderíamos esquecer. Parecia que iríamos reproduzir a mecânica dos itinerários cotidianos, aqueles que nos levavam aos mesmos lugares conhecidos, mas, depois de um tempo, fomos capturadas pela dinâmica do algoritmo e ficamos absortas.

Era um dia de céu encoberto e, antes de atingirmos o cruzamento entre duas avenidas principais da região, entramos à esquerda. As ruas serpenteavam em curvas ascendentes. Nesta topografia irregular casas, terrenos baldios, galpões e pequenas fábricas se intercalavam entre cachorros, passagens inesperadas e asfalto cinzento. Mas, apesar da impressão inicial de que as pessoas que habitavam aquelas paragens

\footnotetext{
9 Conceito proveniente do campo da matemática que consiste em uma sequência de instruções que devem ser seguidas para a resolução de um problema.

10 Proposta de errância urbana baseada no conceito de psicogeografia desenvolvido pelos situacionistas, que realizaram derivas pelas ruas de Paris entre as décadas de 1950-1970. Para mais detalhes vide: https://www.spacehijackers.org/html/ideas/writing/socialfiction.html. Acesso: jun. 2018.
} 
estavam ausentes ou reclusas intramuros, repentinamente percebemos que a cada quarteirão percorrido havia uma presença constante, a qual nos espreitava devidamente posicionada em uma esquina - um homem de meia idade, nos observava sem lançar diretamente seu olhar, ao menos em uma perspectiva frontal. Primeira à esquerda, segunda à direita, segunda à esquerda. Era um homem de olhar atravessado, de viés e agudo. Primeira à esquerda, segunda à direita, segunda à esquerda. Ao mesmo tempo em que achávamos estar perdidas nas reentrâncias daquelas ruas circulares, repentinamente reencontrávamos aquele olhar, aquele homem, em outra esquina uma, duas, três... Primeira à esquerda, segunda à direita, segunda à esquerda. Parecíamos rodopiar em um labirinto nublado em que a única certeza era a de que encontraríamos novamente aquele homem enviesado. Primeira à esquerda, segunda à direita, segunda à esquerda. A ansiedade aumentava, pois parecia que quanto mais andávamos mais permanecíamos no mesmo lugar e repentinamente reencontrávamos aquele olhar, aquele homem em outra esquina uma, duas, três... Primeira à esquerda, segunda à direita, segunda à esquerda. Na quarta vez decidimos entrar em uma viela, uma daquelas passagens inesperadas que pareciam levar a lugar algum. Paredes altas, arborescentes, se inclinavam sobre nossas cabeças e se espraiavam pelo chão sem asfalto em pequenos vazamentos. Agora, em curvas descendentes parecíamos andar em uma gruta. Mas confiávamos em Walesca que disse que nos levaria de volta a uma das avenidas principais. Andávamos cada vez mais rápido, como se aquele olhar estivesse cravado em nossas costas. Descíamos, descíamos e aquela ambiência parecia nos sufocar. Uma topografia transformada em topofobia11, a emergência de uma paisagem do medo (TUAN, 2005). A relação com a presença constante daquele homem modificou completamente a forma como percebíamos o deslocamento por aquelas ruas a princípio tão vazias, mas que foram preenchidas pelo medo. Inesperadamente, a grande via abriu-se diante de nós como um milagre, aquele espaço largo e retilíneo povoado de praças e estabelecimentos comerciais, pontos de ônibus, transeuntes e um constante movimento de veículos. Enfim, nos sentimos em uma zona de aparente segurança. Um lugar rotineiro embalou os corpos tomados pelo medo.

\footnotetext{
${ }^{11}$ Referência ao conceito de paisagem do medo de Yi-fu Tuan.
} 
Segundo o geógrafo sino-estadunidense Yi-fu Tuan, apesar de a cidade ter sido projetada a princípio como a reprodução de uma ordem cósmica, em um anseio por garantir estabilidade e segurança, esta se desenvolveu historicamente como um aglomerado de ambiências de constante ameaça. Neste sentido, o geógrafo conceitua a criação de topofobias ou paisagens do medo como constructos perceptivos advindos das relações de troca entre corpo e ambiente, as quais não se restringem à experiência individual, mas consistem em fenômenos sociais historicamente constituídos (TUAN, 2005). No contexto em questão, o nosso medo estava relacionado ao fenômeno social do patriarcado que regulava a possibilidade das mulheres se locomoverem no espaço público e remetia a um ideal vinculado ao processo de sedentarização da espécie humana. Conforme afirma Tuan "cada moradia é uma fortaleza construída para defender seus ocupantes humanos dos elementos [ameaçadores]; é uma lembrança constante da vulnerabilidade humana" (TUAN, 2005, p.12). Infelizmente, em uma perspectiva de gênero, nem mesmo a moradia consiste em um porto seguro, diante de tantos casos reportados e mapeados de violência doméstica e feminicídio no Brasil ${ }^{12}$. Ao tratar da relação de medo nas grandes cidades, o autor afirma que uma das motivações para desencadear este afeto seria o contato com o outro, aquela e aquele que são percebidos como a diferença no espaço urbano: estrangeiros, pobres, andarilhos e, neste caso, um homem de meia idade. Desse modo, lidar com o medo em relação aos outros no decorrer de uma aula errática se constitui em um exercício de alteridade radical, se compreendermos a arte de andar pelas ruas como a possibilidade de experimentarmos determinada ociosidade criativa que procura desmantelar construções sociais, históricas e culturais da insegurança e do medo em relação aos outros urbanos (KANASHIRO; MARQUES, 2018).

Ainda ao tratar dos vínculos entre medo e espaço urbano, Tuan se utiliza de uma metáfora recorrente para descrever a cidade, a metáfora da cidade como selva, um ambiente que foge ao controle da planificação urbana, no qual até os ruídos artificialmente produzidos por veículos, maquinários e de procedência desconhecida podem consistir em um poderoso efeito desorientador e, portanto, em uma possível

12 Vide dados compilados pela edição atual do Atlas da Violência: http://www.ipea.gov.br/portal/index.php?option=com_content\&view=article\&id=33410\&Itemid=432. Acesso: jun. 2018. 
ameaça. Embora o autor não tenha se atentado às especificidades das relações de gênero em seu trabalho, a metáfora da cidade selva pode nos interessar aqui enquanto uma maneira de refletirmos a respeito do modo como percebemos e somos percebidas e percebidos no espaço urbano. Se analisarmos o ocorrido nesta aula errática por meio da metáfora da cidade selva, seria possível inferir que, caso adentrássemos em determinados domínios, estaríamos fadadas a nos tornarmos presas de algum predador. Por isso, era necessário que prestássemos bastante atenção aos locais por onde andávamos. Apesar de não ser possível dizer ao certo quais eram as intenções daquele homem que nos seguia de maneira incisiva a cada esquina, a sensação de ansiedade crescente que aquele olhar infligia nos impulsionou à busca por uma saída imediata.

Este não foi a único escrito errabundo ${ }^{13}$ que enfatizou a ameaça proveniente dos corpos que performam a masculinidade no decorrer das aulas erráticas por Ermelino Matarazzo. Em uma classe composta majoritariamente por mulheres negras, a percepção do ato de andar pelos arredores do bairro em que estudavam e algumas moravam poderia levantar suspeitas sobre a decência de seus hábitos e abrir precedentes a respeito de sua disponibilidade para práticas sexuais. Dessa forma, o entorno parecia ser constituído por olhares machistas, provenientes não só de homens, mas também de mulheres que acionam as dinâmicas de manutenção do poder patriarcal, que observam e julgam a conduta dos corpos que performam o gênero feminino no espaço urbano. Estavam cumprindo seus compromissos? Estavam vestidas adequadamente? Estavam acompanhadas? Eram conhecidas? E se fossem, o que estariam fazendo na rua naquele horário em que deveriam estar estudando? Esta última pergunta era uma das mais ameaçadoras para algumas daquelas mulheres, as quais desafiaram muitas barreiras para conseguirem voltar aos estudos. Pois, tais questionamentos poderiam significar que em breve qualquer pessoa legitimada pelo patriarcado a assumir uma postura de posse sobre essas mulheres, estaria ciente de que em algum momento do dia suas mulheres desviaram do que estava programado para as suas rotinas. Dessa maneira, a experiência daquelas aulas erráticas

\footnotetext{
13 Nomenclatura utilizada pelo Coletivo Parabelo para se referir aos escritos produzidos a partir da experiência com as errâncias urbanas.
} 
demonstrava que, em grande parte das vezes que nós mulheres saíamos às ruas sem um destino certo, um lugar certo e na hora certa, poderíamos estar sob as mais variadas ameaças do medo.

A partir dessa visão metafórica da cidade selva, é possível inferir que a presença dos corpos que performam o gênero feminino nos mais diversos espaços, poderia reduzir-se a uma genitália sob um olhar onipresente, objetificante e sexista. Este parecia, então, um fenômeno inerente ao processo de socialização das mulheres, que interfere diretamente na percepção de suas relações com o espaço urbano. Um fenômeno legitimado junto à ideia moderna de cidade e ao entendimento de que as mulheres das classes abastadas deveriam se confinar aos afazeres do âmbito doméstico, a fim de garantir a decência e a pureza da estirpe ${ }^{14}$, enquanto as mulheres da classe trabalhadora tanto assalariada quanto escrava estão expostas a todo tipo de assédio e violência ao circularem pela cidade. A partir dos estudos da escritora e teórica feminista Rebecca Solnit (2016) é possível afirmar que a locomoção das mulheres pelo espaço público assume cultural, social e historicamente um caráter sexual, em um contexto regido pelo patriarcado. Segundo a autora, uma mulher que anda pelas ruas sem maiores preocupações parece ser uma afronta. À medida em que movimenta os quadris e meneia a cabeça, seu andar se torna uma provocação, a parte frontal de seu corpo pode ser descrita como seios e genitália, enquanto a traseira enche a boca de impropérios. Neste caso, é premente lembrarmos que, segundo a antropóloga brasileira Lélia González, esse processo de reificação do corpo que performa o gênero feminino é ainda mais efetivo quando se trata das mulheres negras, devido ao nosso passado colonial que insiste em se fazer presente. A autora discute a origem do termo mulata, cunhado em período colonial, não só como sinônimo de mestiçagem, mas da ostentação de uma mercadoria sexual tipo exportação, a personificação da negra devassa. Este olhar objetificante lançado sobre os corpos que performam o gênero feminino parece transformar a sexualidade destes em um fardo, algo que jamais passaria despercebido aos olhares modelados por preconceitos sexistas, mesmo que a mulher em questão estivesse simplesmente andando. Nesta perspectiva, a mulher que

\footnotetext{
${ }^{14}$ A monogamia como uma forma de garantir a afirmativa para o problema de “quem é o pai?", enfim, uma das formas de garantir o domínio masculino, conforme a autora.
} 
circula pelo espaço urbano torna-se acessível, um convite gratuito ao assédio, um convite gratuito à violação. Um corpo exposto à violência. Um corpo interpretado enquanto violência.

$$
* * *
$$

Diante dos automatismos instaurados pela experiência corporal cotidiana urbana, o ato de andar pelas ruas de Ermelino Matarazzo com uma classe de mulheres de diferentes gerações não era uma ação simples, era uma forma de confrontar os medos que se tornavam recorrentes no decorrer das aulas erráticas. Ao propormos a partitura de Yoko Ono, intitulada Map Piece (Peça Mapa)15, como uma forma de percebermos o ato de andar pelas ruas sem rumo enquanto criação artística, para muitas estudantes tudo parecia encoberto pelo medo em diversas acepções. O medo de andar pelas ruas, o medo de ser vista por alguém conhecido, o medo do ridículo, o medo do vazio, o medo de se perder, o medo de sofrer alguma violência, o medo de ser vista como uma vadia, o medo de ser chamada de vagabunda. A experiência que se delineava ao longo das aulas erráticas parecia uma confirmação de que as mulheres andam mal...

As mulheres andam mal. Uma afirmativa generalizante com sentidos variáveis e uma grande probabilidade de ser algo que desqualifica corpos que performam o gênero feminino. Afirmativa que converge para preconceitos socialmente constituídos em torno da mulher frágil, doce, meiga, afeita aos afazeres domésticos, receosa dos espaços públicos. Por meio dessa lógica sexista, legitimada inclusive por pesquisas científicas no campo da antropologia, as mulheres andam mal por serem inaptas a percorrer longas distâncias. Conforme estudos realizados por Rebecca Solnit (2016), dentre as diversas teorias que estão em desenvolvimento em torno do bipedalismo - a passagem do parentesco com os primatas, quadrúpedes, para a atual postura ereta da

\footnotetext{
15 A partitura desta peça, datada de 1962, propõe: "Desenhe um mapa imaginário. Marque um ponto no mapa aonde deseja ir. Caminhe por uma rua verdadeira segundo seu mapa. Se não existe rua onde deveria haver segundo o mapa, faça uma colocando de lado os obstáculos. Quando alcançar a meta, pergunte o nome da cidade e dê flores à primeira pessoa que conhecer. O mapa deve ser seguido exatamente, ou o evento deverá ser totalmente abandonado. Peça aos amigos que escrevam mapas. Dê mapas aos amigos". Disponível em: https://monoskop.org/images/9/95/Ono_Yoko_Grapefruit_O_Livro_de_Instrucoes_e_Desenhos_de_Yoko_ Ono.pdf. Data de acesso: jun. 2018.
} 
espécie humana que se locomove sobre os dois pés -, grande parte destas teorias reflete de alguma forma concepções sexistas em relação à fêmea da espécie humana. A autora parte de um reconhecido artigo do antropólogo estadunidense Owen Lovejoy no qual este propõe que, pelo fato da fêmea da espécie possuir uma estatura menor em relação ao macho, teria mais dificuldades para se locomover, suas pernas eram encurtadas e o quadril alargado pela combinação de adaptações biológicas que tornaram possível conciliar o parto e o andar ereto. Esta revolução da conformação óssea da espécie humana, que ocorreu durante milhares de anos para conquistar a postura ereta, se constitui em uma violenta modificação do corpo que, durante a gravidez, desenvolveu estratégias anatômicas para que a cartilagem da ossatura pélvica fosse capaz de se separar para abrir espaço à passagem do crânio do bebê. Uma transformação fabulosa que, ao mesmo tempo, é tratada por alguns estudiosos como a maldição do Gênesis, ao culpar a fêmea da espécie por não permitir que o crânio e o cérebro sejam maiores e, portanto, limitar o desenvolvimento da inteligência humana, em uma perspectiva cartesiana que separa corpo e mente e localiza a inteligência nas funções cerebrais (SOLNIT, 2016).

Ainda em torno da função materna, Solnit aponta para teorias que justificam um processo de sedentarização da mulher, a qual deveria permanecer em local protegido para cuidar da prole e depender, dessa forma, da provisão masculina. Além disso, por conta de teorias as quais afirmam que quanto menor a fêmea maior a possibilidade de práticas sexuais poligâmicas, a reclusão da fêmea seria uma forma de defender o território e estabelecer quem era o pai daquela prole. Neste âmbito, a conformação óssea para a maternidade, os cuidados com a prole e a progressiva sedentariazação narrada por estas teorias constituem argumentos para afirmar que as mulheres andam mal e apontam para uma possível genealogia do patriarcado, isto é, uma genealogia da ordenação social que aceita a ideia de uma suposta supremacia masculina em um regime de dominação e exploração imposto às mulheres (SAFFIOTI, 2015). Nesta perspectiva, as mulheres são reduzidas às funções histórica e culturalmente delegadas a estas, as funções maternas, sexuais e de cuidadora em todos os âmbitos. Assim, os corpos que performam o gênero feminino precisam servir e se restringir ao âmbito privado, precisam carregar o fardo dos discursos que 
desqualificam suas possibilidades de estar no espaço público, ao reforçarem constantemente o fato de que as mulheres andam mal.

Conforme as performances, as cartografias do medo se faziam cada vez mais nítidas em nossas aulas erráticas, um questionamento se tornava premente: por que não conseguíamos fazer como aqueles errantes urbanos, homens brancos, europeus, vistos como boêmios e aventureiros que desbravavam cidades como Paris ao praticarem a arte de andar pelas ruas sem rumo certo, ao menos desde meados do século XIX? A partir desse questionamento, de acordo com as genealogias da performance realizadas pelo Coletivo Parabelo, é possível observar que há um predomínio de experiências masculinas, brancas e europeias na prática das errâncias urbanas. Por exemplo, se considerarmos as flanâncias enquanto a arte de perder-se pela e na experiência do choque com as multidões emergentes nos boulevards das grandes cidades do final do século XIX, podemos destacar o poeta francês Charles Baudelaire como um dos mais emblemáticos flâneurs ${ }^{16}$. Conforme é sabido, o autor concebeu um de seus poemas mais canônicos a partir das suas flanâncias. Trata-se do clássico A uma passante, que descreve a aparição de uma mulher no espaço público de modo anônimo, fugaz e evanescente. Já no que toca as visitas dadaístas aos espaços banais do cotidiano parisiense no começo do século XX, observamos registros fotográficos que documentam um grupo composto exclusivamente por homens brancos, europeus, engravatados, ostentando chapéus e bengalas. Por sua vez, nas deambulações surrealistas realizadas na capital francesa em meados do século XX, enquanto investigava a participação do inconsciente no processo de orientação, desorientação e reorientação corporal tal qual numa escrita automática feita ao acaso no cotidiano maravilhoso da cidade onírica, André Breton narra uma série de encontros e desencontros com a Nadja em um livro homônimo. Nesse caso, a Nadja consistia na aparição de uma mulher na esfera pública ao assumir o famigerado posto de musa misteriosa, sedutora e inspiradora. De acordo com os exemplos expostos nesta breve genealogia da performance, mesmo no período que marca a passagem da arte

${ }^{16}$ É importante lembrar que o substantivo flâneur na língua francesa, além de remeter a um tipo específico de errante urbano, também significa vagabundo(a) e vadia(o). 
moderna para a arte contemporânea as mulheres são negligenciadas enquanto artistas, criadoras e propositoras ao permanecerem aparecendo não só como tema, conteúdo e modelo, mas sobretudo por emergirem sob a lógica da predação sexista: os corpos que performam o gênero feminino surgem como o alvo das objetificações e das fetichizações masculinas.

Mas, ao considerarmos esta genealogia dominante das errâncias urbanas pela perspectiva de uma crítica interseccional, relativa a questões de gênero, classe e raça, encontraremos mulheres que experimentaram a arte de andar pelas cidades desde o final do século XIX. Mulheres que andam mal ao desobedecerem às regras preestabelecidas para a sua existência nas grandes cidades. Desse modo, as chamadas flâneuses eram mulheres que praticaram a arte de perder-se pela e na experiência do choque com as multidões em Paris, em um exercício de liberdade. Apesar de possuírem um reduzido número de possibilidades para ter alguma garantia de permanência no espaço público - ou eram vistas como mulheres selvagens, altamente sexualizadas, vadias por desafiarem as normas, ou tornavam-se invisíveis ao se travestirem e andarem como se fossem homens. Assim, segundo a escritora e teórica literária estadunidense Lauren Elkin (2016), as flâneuses andavam por lugares em que supostamente não deveriam estar. Por meio desse viés crítico, nos remetemos também às fluxus, que surgiram no decorrer dos anos 1960-1970, promovidas pela comunidade artística Fluxus, da qual Yoko Ono faz parte. As fluxus consistiam na arte de andar atentamente nos e pelos fluxos que constituem a relação corpo cidade. Para tanto, foram difundidas por meio de partituras que podem ser executadas por qualquer pessoa, com o intuito de tornar o fazer artístico uma prática cotidiana comum e compartilhada, o que na perspectiva desenvolvida aqui, implica necessariamente em colocar em fluxo os papeis de gênero que configuram a esfera privada e a esfera pública. Para além disso, citamos as persecuções promovidas pela artista francesa Sophie Calle, em Suite Venitienne (Suíte Veneziana), no final dos anos 1970, ocasião na qual a artista reverteu a lógica da cidade selva quando ela se propôs perseguir um homem pelas ruas de Veneza, tornando-o sua presa ${ }^{17}$. Por último, mas não menos

\footnotetext{
17 Para mais detalhes vide: CALLE, Sophie. Suite Venitienne. New York: Distributed Art Pub Incorporated, 2015.
} 
importante, destacamos as catalisações realizadas pela artista afro-estadunidense Adrian Piper durante a década de 1970. Na catalisação intitulada The Mythic Being (O Ser Mítico), Piper performa os diversos estereótipos construídos social, cultural e historicamente em torno da ideia de masculinidade, ao se travestir e andar pelas ruas de Nova York. Em um de seus escritos, a artista sugere presentificar um dos maiores medos sociais instituídos pelo racismo - um homem negro que circula pelo espaço

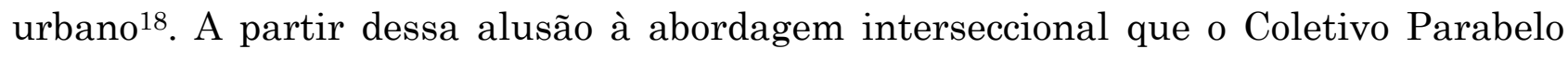
tem desenvolvido acerca da arte da performance, muitas histórias ainda permanecem apagadas e necessitam ser reescritas, para que possamos compreender de que modos os corpos que performam o gênero feminino promovem a politização do corpo ao ampliar a noção de artisticidade nas e pelas práticas das errâncias urbanas. Dessa forma, errar implica em subverter o sentido para a afirmativa de que as mulheres andam mal. As mulheres andam mal quando transgridem as lógicas do patriarcado que configuram as esferas privada e pública.

No decorrer das aulas erráticas emergiram histórias das experiências de vida de mulheres pretas, pobres e periféricas na cidade. Eram histórias de violências sofridas tanto em espaços públicos quanto em âmbito doméstico, como memórias desencadeadas nas e pelas aulas erráticas em Ermelino Matarazzo. Alicia nos contou dos problemas enfrentados em seu primeiro casamento, era muito jovem e se submeteu à proibição de sair de casa, vivendo durante quatro anos uma relação de cárcere privado. Maria levou um tiro ao defender sua irmã da morte pelo marido e sobreviveu para contar. Julia foi estuprada pelo rapaz que ela, em uma relação platônica, fantasiava ser o seu namorado. Sandra deixava sua filha de dez anos sob os cuidados dos avós quando saía para trabalhar, demorou muito tempo para aceitar que seu próprio pai, avô da criança, violentava sua filha e se culpa até hoje, apesar de ter entrado com um processo judicial. Juçara teve que enfrentar diariamente o assédio no ambiente de trabalho, como empregada doméstica precisava se esquivar com frequência do patrão, até o dia em que teve de se defender com uma panela e foi demitida. Estávamos diante de perfografias do machismo, abusos constituídos

\footnotetext{
18 Para mais detalhes vide: PIPER, Adrian. Out of order, out of sight. Cambridge: MIT Press, 1999.
} 
enquanto atos de poder que almejavam reafirmar constantemente uma suposta supremacia masculina. O que fazer diante destas histórias que reapresentavam no espaço da sala de aula a realidade cotidiana de muitas mulheres não só negras, nem restritas à classe trabalhadora, mas de todas as condições socioeconômicas e de diferentes ascendências? A princípio estas histórias de violência traziam uma crescente sensação de impotência. Ao mesmo tempo, parecia que o fato de ter um espaço para relatar aquelas experiências traumáticas acabava, de certa forma, sendo um alívio momentâneo e um modo de pensarmos a respeito do que fazer com aquelas dores que deixavam de ser privadas e se tornavam públicas em uma relação de sororidade. Não era possível permitirmos que aquelas dores persistissem como pesados fardos carregados cotidianamente, como se fossem um dado natural em relação à existência das mulheres que, segundo uma visão sexista, aparentemente andavam mal por não conseguirem esconder suas fragilidades.

Diante desse impasse, a máxima feminista do final dos anos 1960 parecia mais presente do que nunca: "o pessoal é político" 19. Esta frase foi e ainda é um estopim para a compreensão da condição de exploração e dominação das mulheres não como um problema doméstico, de cunho particular, mas um problema de interesse público que se reflete em todos os níveis da sociedade. Um estopim que nos trouxe à tona a lembrança de uma mulher que, em 1977, dedicou três semanas do mês de maio - mês das mães, mês das noivas - para ações performáticas em protesto contra a onda de estupros que assolava os Estados Unidos neste período. Era a professora performer pesquisadora estadunidense Suzanne Lacy que tinha algo a nos mostrar naquele momento, através do estudo de seu trabalho intitulado Three Weeks in May ${ }^{20}$.

Em meio às grandes mobilizações dos movimentos feministas em diversas frentes no decorrer dos anos 1970, dentre estas a campanha antiestupro nos Estados

\footnotetext{
${ }^{19}$ Máxima popularizada a partir de texto da ativista estadunidense Carol Hanisch. Para mais detalhes vide: https://we.riseup.net/assets/190219/O+Pessoal\%2Bé\%2BPolítico.pdf

${ }^{20}$ É importante mencionar que Suzanne Lacy foi aluna de Judy Chicago (1939), artista estadunidense feminista reconhecida por seu trabalho com instalações e do professor performer pesquisador Allan Kaprow (1927-2006) considerado um dos pioneiros da arte da performance. A organização de Three Weeks in May contou com a participação de Leslie Labowitz, Melissa Hoffman, Anne Gauldin, Laurel Klick, Judith Loischild, Cheri Gaulke, Barbara Smith Barbara Cohen, Melissa Hoffman, Jill Soderholm, dentre outras. Mais detalhes vide: http://www.suzannelacy.com/three-weeks-in-may/. Acesso: jun. 2018.
} 
Unidos, liderada principalmente por mulheres brancas ${ }^{21}$, junto a uma tendência crescente nas artes visuais que convocava a presença do corpo artista em ação em detrimento do objeto artístico - ao enfatizar a ideia de desmaterialização da obra de arte; Lacy organizou em conjunto com outras artistas e ativistas uma série de ações em Los Angeles relativas à prática do estupro e amplamente divulgadas pela imprensa local. Tais ações se desenrolaram ao longo de três semanas tendo como ponto de partida um trabalho de Lacy, anteriormente apresentado em uma galeria, intitulado Maps (Mapas) o qual, nesta ocasião, se deslocou do espaço exclusivo das artes para ganhar o espaço público, aberto à participação de pessoas que muitas vezes não teriam acesso aos espaços expositivos convencionais. Este trabalho consistia na exibição de dois grandes mapas da cidade de Los Angeles colocados lado a lado, sendo que em um a palavra rape (estupro) era gravada em tinta vermelha nos locais em que algum caso de estupro era reportado, (dados estes recolhidos diariamente em um departamento central de polícia da cidade). Ao redor dessa palavra em destaque carimbava-se a mesma palavra nove vezes em fonte vermelha vasada, para representar a estimava de que a cada caso de estupro reportado nove haviam ocorrido sem que as vítimas denunciassem.

Já o outro mapa indicava os endereços de centros de referência de apoio às vítimas desse tipo de violência. A partir desse mapeamento, artistas e ativistas se dirigiam aos locais em que o estupro havia ocorrido e gravavam em tinta vermelha a silhueta de um corpo com uma flor na altura do coração, acompanhada de escritos informando a data e quantidade de mulheres violentadas nas proximidades daquele local. Além dessas ações, no decorrer de três semanas ocorreram aulas públicas de defesa pessoal para mulheres, ações em frente a lojas de departamento, reuniões entre autoridades e ativistas e a montagem da instalação She who would fly (Aquela que deveria voar), na qual relatos de estupros sofridos por diferentes mulheres tiveram visibilidade. Desse modo, Three weeks in may se tornou um dos trabalhos mais

\footnotetext{
${ }^{21}$ Importante lembrar que, segundo a filósofa e ativista Angela Davis, o movimento antiestupro foi iniciado pelas mulheres negras estadunidenses ainda no final do século XIX, a partir da crescente criminalização dos homens negros e de outras minorias étnicas pela prática de estupro. Para mais detalhes vide: DAVIS. Angela. Mulheres, raça e classe. Trad. Heci Regina Candiani. São Paulo: Boitempo, 2016.
} 
emblemáticos de Suzanne Lacy, o qual pode ser abordado pelo viés do que a artista denominou posteriormente de New Genre Public Art (Novo Gênero de Arte Pública) ${ }^{22}$. Curiosamente, outro gênero de arte pública emerge justamente quando se torna impossível a indiferença diante das violências de gênero sofridas publicamente por aquelas relegadas social, histórica e politicamente ao posto do outro ${ }^{23}$.

Assim, nos propusemos a pensar, inspiradas pelas práticas artísticas de Suzanne Lacy, no que poderíamos fazer ao longo de três semanas de aulas erráticas no mês de novembro, em Ermelino Matarazzo. Muitas propostas foram cogitadas na relação com o trabalho de Lacy, realizado há quatro décadas atrás e as perfografias daquele bairro de São Paulo. Então, prosseguimos com as aulas erráticas ao irmos à delegacia da região e conseguirmos ter acesso a alguns dados em torno dos casos de violência contra as mulheres daquele bairro. Pintamos em vermelho silhuetas de corpos próximas aos locais em que ocorreram estupros relatados na região de Ermelino Matarazzo. Realizamos leituras e conversas sobre a Lei Maria da Penha, a qual completaria 10 anos de implementação no ano seguinte. Organizamos um debate com autoridades locais e estudiosas da questão de gênero. Escrevemos, recolhemos e montamos uma exposição de relatos de violência em uma árvore localizada em região de grande movimento do bairro, a qual denominamos Árvore da Violência, ao nos referirmos à Árvore dos Desejos (Wish Tree) proposta por Yoko Ono ${ }^{24}$. Encerramos a série de aulas erráticas com uma marcha em protesto aos casos de violência contra a mulher, inspirada nos protestos realizados em Three Weeks in May ${ }^{25}$. Nesta aula, nos

\footnotetext{
22 Termo cunhado em 1991 pela artista, para diferenciar o entendimento de arte pública dos monumentos que legitimam uma história oficial, das práticas artísticas que acionam a participação no âmbito da esfera pública.

${ }^{23}$ Conforme estudos desenvolvidos por diversas teóricas feministas, como Simone de Beauvoir, a mulher tem sido constantemente relegada à condição do "outro" no sentido da diferença discriminatória e do processo de inferiorização relativo aos corpos que performam o gênero masculino, como se estes fossem modelo inquestionável para constituição de um suposto sujeito universal.

24 Vide escrito publicado no blog da escola por uma das estudantes que participou dessas aulas: http://ciejaematarazzo.blogspot.com/2016/02/abrindo-os-olhos.html.

${ }^{25}$ Cabe ressaltar a existência e permanência de diversas marchas feministas, em contextos variados, ao longo do século XX e neste início de século XXI. Destacamos, neste caso, a Marcha das Vadias (Slutwalk) que data de 2011. Para mais detalhes vide: https://marchadasvadiascwb.wordpress.com/conheca-a-marcha/porquevadias/. E também a Marcha das Mulheres Negras, a partir da instituição da data 25 de julho como dia da Mulher Negra Latina e Caribenha em 1992. Mais detalhes vide: https://www.geledes.org.br/as-origens-do-dia-da-mulher-negralatina-e-caribenha/. Acesso: jun. 2018.
} 
vestimos com roupas pretas, pintamos palavras relacionadas à violência no rosto, pernas, braços, colo, costas. Algumas vendaram os olhos com faixas de gaze, outras pintaram e ostentaram cartazes com frases de efeito. Andamos em dupla, de mãos dadas e em silêncio pelas ruas. Permanecemos em cruzamentos, faixas de pedestre, hospitais e postos policiais. Fomos abordadas pela segurança da estação de trem e aplaudidas por um grupo de mulheres. Alguns pensaram que fazíamos parte do movimento de apoio às escolas ocupadas naquele mesmo período ${ }^{26}$. Fomos xingadas "vai lavar um tanque de roupa suja, suas vadias!" e ignoradas. Quando andávamos por uma das avenidas principais do bairro, um grito de dentro do transporte coletivo atravessou muros e janelas. "Eu sou mulher e ando armada!". Palavras que ecoaram durante muito tempo. Era necessário falar sobre medos e violências, era necessário gritar para se fazer ouvida em certos momentos.

Portanto, aquelas aulas erráticas fizeram mais do que abrir espaço para experimentarmos as errâncias urbanas como possibilidade de exercitar uma ociosidade criativa popularmente conhecida como vagabundagem. Aquelas aulas erráticas nos ensinaram que para os corpos que performam o gênero feminino não há vagabundagem sem vadiagem, sem transgressão dos valores inventados em torno do que deve ou não ser uma mulher, a partir de um contrato sexual firmado historicamente pelo regime patriarcal. Por isso, as aulas erráticas se transformaram em aulas vadias quando mulheres pretas, pobres e periféricas desafiaram os contratos patriarcais, racistas e classistas que configuram as impossibilidades de circulação dos corpos que performam o gênero feminino tanto na esfera privada, quanto na esfera pública. As mulheres efetivamente andam mal? A partir das nossas aulas vadias, aprendemos que as mulheres somente andam mal ao negarem os destinos profetizados para suas existências pela sociedade patriarcal.

Nesse sentido, cabe compartilhar uma última lição aprendida junto ao Coletivo Parabelo na criação das nossas aulas vadias: não podemos esquecer que ainda está em vigência um código penal que data de 1941, em que a prática da vadiagem ${ }^{27}$ é

\footnotetext{
${ }^{26}$ Em referência às ocupações das escolas, realizadas pelo movimento secundarista em 2015.

${ }^{27}$ Definida como: "entregar-se alguém habitualmente à ociosidade, sendo válido para o trabalho, sem ter renda que lhe assegure meios bastantes de subsistência, ou prover à própria subsistência mediante ocupação ilícita”. Disponível em: http://www.camara.gov.br/sileg/integras/290126.pdf. Acesso: jun. 2018.
} 
considerada crime e há controvérsias em torno da sua revogação. Esta lei é um exemplo de criminalização da pobreza diretamente relacionada a outras legislações que criminalizaram a precariedade da vida dos ex-escravizados, africanos e afrodescendentes, os quais passaram pela abolição sem que houvesse qualquer iniciativa pública relacionada à inclusão destes no novo modelo de sociedade que se instalava, com a contratação de mão de obra assalariada. Lei que criminaliza não apenas mulheres como também homens responsáveis por garantir o próprio sustento e dos demais que deles dependam em ocupações não formais. Lei cuja origem remonta ao código penal brasileiro de 1890, no qual a prática da vadiagem está associada à prática da capoeira em espaços públicos, o que por si só evidencia sua conotação racista ao criminalizar uma manifestação cultural de matriz afro-brasileira. Lei que igualmente possibilitou a prisão de muitas pessoas durante os regimes ditatoriais brasileiros. Lei que desconsidera os fatores de desintegração social em curso em metrópoles como São Paulo. Lei a partir da qual constatamos que toda norma produz sua efetividade por meio da mobilização dos afetos nos e pelos corpos de cada um de nós. Como, por exemplo, o medo de ser vadia.

\section{REFERÊNCIAS}

BAITELLO JR., Norval. O pensamento sentado: sobre glúteos, cadeiras e imagens. Porto Alegre: Editora Unisinos, 2012.

ELKIN, Lauren. A tribute to female flâneurs: the women who reclaimed our city streets. In The Guardian, online, 29 jul. 2016. Disponível em: https://www.theguardian.com/cities/2016/jul/29/female-flaneur-women-reclaim-streets. Acesso: jun. 2018.

GONZALEZ, Lélia. Racismo e sexismo na cultura brasileira. In: Revista Ciências Sociais Hoje, Anpocs, p. 223-244, 1984.

JACQUES, Paola Berenstein. Elogio aos errantes. Salvador: EDUFBA, 2012. 
KANASHIRO, Bárbara; MARQUES, Diego Alves. Corpos inconformados: arte e educação nas práticas artísticas contemporâneas. In ANDRE, Carminda Mendes; BAPTISTA, Ana Maria Haddad (org). Pedagogias em trânsito: estudos para uma ecologia de saberes em arte educação. São Paulo: BT Acadêmica, p. 155-195, 2018.

LACY, Suzanne. Debated territory: toward a critical language for public art. In LACY, Suzanne (ed). Mapping the terrain: new genre public art. Seattle: Bay Press, p. 171185,1996.

MARQUES, Diego Alves. Virada pedagógica: o Coletivo Parabelo e a revolta da carne do assento. In Revista Rascunhos Uberlândia v.4 n.1, p.118-132, jan. |jun.2017. MARQUES, Diego Alves; RACHEL, Denise Pereira. Perfografia: performance como cartografia, performer como cartógrafo. In Revista Redobra, n. 11, Salvador, UFBA, p. 152-161, 2011. Disponível em: http://www.redobra.ufba.br/wpcontent/uploads/2013/06/redobra11_17.pdf.

RACHEL, Denise Pereira. Adote o Artista não deixe ele virar professor: reflexões em torno do híbrido professor performer. São Paulo: Editora Unesp, Selo Cultura Acadêmica, 2015. Disponível em: http://www.culturaacademica.com.br/catalogodetalhe.asp?ctl_id $=467$

ROLNIK, Suely. Cartografia Sentimental: transformações contemporâneas do desejo. São Paulo: Estação Liberdade, 1989.

SAFFIOTI, Heleieth. Gênero patriarcado violência. São Paulo: Expressão Popular: Fundação Perseu Abramo, 2015.

SCHECHNER, Richard. Performance studies: an introduction, second edition. New York: Routledge, 2002.

SOLNIT, Rebecca. A história do caminhar. Trad. Maria do Carmo Zanini. São Paulo: Martins Fontes, 2016.

TUAN, Yi-fu. Paisagens do medo. Trad. Livia de Oliveira. São Paulo: Editora UNESP, 2005.

Recebido em agosto de 2018. Aprovado em outubro de 2018. Publicado em dezembro de 2018. 